\title{
VISIÓN Y ANÁLISIS DE LA PRENSA EN MEMORIAS DE UN SETENTÓN, DE RAMÓN DE MESONERO ROMANOS
}

\author{
Enrique RUBIO CREMADES \\ Universidad de Alicante
}

Los diccionarios publicados en el siglo XIX y albores del XX recogen y explican el término Memoria con un significado preciso: relación de algunos acaecimientos particulares que se escriben para ilustrar la historia o relación escrita en que el autor narra su propia vida o acontecimientos de ella. En la Memoria el autor se propone dar cuenta de aquellos hechos en los que él mismo ha participado o que sólo ha estado en situación de conocer circunstancialmente. Las Memorias, que pueden llamarse materiales para la historia, siguen rigurosamente un orden cronológico. La explicación del término ofrecida por los diccionarios publicados en la segunda mitad del siglo XIX no varía sustancialmente de la ofrecida en publicaciones de parecida índole editadas recientemente. Los diccionarios de términos literarios actuales señalan, por ejemplo, que se trata de un relato autobiográfico, escrito en retrospectiva, y en el que una persona real narra acontecimientos relevantes de su vida, enmarcados en el contexto de otros acontecimientos de muy diversa índole o contenido. Los límites fronterizos existentes entre el género Memoria y sus diversas modalidades, como el diario, autorretrato, recuerdos, confesiones, autobiografías, etc., indican también cuan complejo es el análisis exacto del referido género'. Afortunadamente existe hoy en día un material noticioso de gran valor que está en clara contradicción con la opinión

' Límites fronterizos que, en ocasiones, son de difícil precisión. José Escobar ha analizado puntualmente las Memorias de un setentón desde esta precisa óptica. Para el citado crítico, Mesonero, al adoptar el título de Memorias «registra la diferenciación conceptual de los términos memorias y autobiografías que fuera de España se había establecido en la reflexión crítica sobre la abundante litera- 
orteguiana (España es el país que menos memorias ha escrito $)^{2}$ y que demuestra o hace patente la existencia de un rico y sustancioso número de obras adscritas al género y publicadas en los siglos XIX y $\mathrm{XX}^{3}$.

La obra Memorias de un setentón figura siempre en un lugar señero entre las publicaciones que de su misma índole aparecieron en el siglo XIX; sin embargo, no nos vamos a centrar en la importancia o incidencia que dicha publicación

tura reminiscente. Con el término memorias desde hacía ya mucho tiempo, se designaba en el extranjero, no sólo en Francia, sino también en los países de lengua inglesa, un género de escritos que caían dentro de la definición anunciada por el autor de los Recuerdos literarios [Escosura]", (1993, pág. 282). En sus conclusiones $\mathbf{J}$. Escobar señala que no existe una frontera clara entre las memorias y la autobiografía. El autor de memorias, entendidas como texto estético, no puede ser un simple cronista, registrador de unos hechos pretéritos, pues la «presencia de su personalidad, desde el presente, es indispensable en el texto de este género de escritos. El pasado, en cuanto rememoración, se nos representa experimentado, vivido. Mesonero, aunque rechaza el término autobiografía, rehuyendo el exhibicionismo personal como temática de sus reminiscencias, no tiene más remedio que "combinar en cierto modo los sucesos extraños que relata con la propia modestísima biografía". Si bien, esta expresión B "su propia modestísima biografía"- no es más que una atenuación del término fuerte autobiografa» (1993, págs. 285-286).

${ }^{2}$ Los testimonios de la crítica que figuran al final de tomo segundo de las Memorias de un setentón (1881) han creado una imagen negativa al respecto, pues se alude e insiste en la escasez de obras españolas referentes al género autobiográfico. El Apéndice que figura en dicha edición es un mosaico de opiniones de gran interés para el crítico, pues no sólo se teoriza sobre el género al que pertenece la obra, sino también sobre la incidencia o importancia del mismo en la literatura europea. El marqués de Valmar señala al respecto que en España «se echan de menos las Cartas y las Memorias, que tan fructuosamente sirven en otras naciones como explanación o complemento de la Historia [...] las Memorias y las Cartas atienden más a la realidad sencilla de las cosas, e individualizando los hechos y refiriendo interesantes pormenores, dan a la narración más carácter novelesco o dramático. De esta diferencia puede servir de ejemplo la pintura que del año del hambre hacen respectivamente la Historia del Conde Toreno y las Memorias de un setentón [...]» (1881, II, págs. 224-225). Los juicios de José Mañé y Flaquer, Manuel de la Revilla, Francisco de Asís Pacheco, Rafael Luna [Matilde Cherner], entre otros, inciden en este aspecto y en otros relacionados con las fuentes literarias de las Memorias y la actitud de Mesonero en la relación de los sucesos y hechos descritos.

${ }^{3}$ En contraposición a la opinión generalizada de la época centrada en la escasa producción en España de la literatura autobiográfica, surgen en estas últimas décadas voces en clara contraposición a dichas opiniones. Anna Caballé (1995) analiza el copioso material existente en la España del siglo XIX. En sus conclusiones indica que «es sorprendente la abundancia de escritos autobiográficos a lo largo del siglo XIX: periodo convulso, pleno de cambios profundos en todos los órdenes de la vida: el tránsito de una sociedad estamental a una sociedad clasista, la intensidad de los acontecimientos políticos, los constantes enfrentamientos ideológicos, la transformación de las costumbres, del arte, de la ciencia..., convierten el siglo XIX en un friso espectacular donde tendrán cabida los más variados testimonios (con frecuencia acompañados de una documentación que acredite lo escrito) [...] De modo que strictu sensu no hay razón que justifique seguir manteniendo la vigencia del tópico de nuestra escasez en ese dominio literario» (1995, págs. 135-136).

Un amplio corpus bibliográfico sobre todo este material referido a la autobiografía española lo encuentra el lector en Fernando Durán López (1997). Vid. también las investigaciones llevadas a cabo en el seno del Instituto de Semiótica Literaria, Teatral y Nuevas Tecnologías de la UNED (Romera Castillo, 1999) 
tuvo en el género, ni tampoco en la veta costumbrista de tipos y escenas que subyace en sus Memorias. Mi interés radica en el específico campo de la prensa periódica, en las reseñas, opiniones y juicios de Mesonero Romanos sobre dicho género, habida cuenta de que su testimonio es fundamental por ser el fundador de $E l$ Semanario Pintoresco Español, revista que marca las pautas y sirve como modelo a las posteriores revistas literarias e ilustradas del siglo XIX (Rubio Cremades, 2000). Su labor como periodista es el mejor aval para tener en cuenta sus opiniones sobre la prensa de la primera mitad del siglo XIX, pues sus juicios permiten establecer una clara disección de todo este material periodístico, tanto desde la óptica ideológica como de la perspectiva de la propia calidad e interés de la publicación citada.

Las primeras referencias a la prensa periódica insertas en sus Memorias nos remiten a su época de adolescente y a un ambiente familiar caracterizado por la bonanza de los negocios paternos. En este preciso contexto, Mesonero Romanos confiesa que pudo observar los diferentes comportamientos del ser humano gracias a las visitas que su padre recibía en casa. Como si de una galería de tipos se tratara, el novel escritor tiene ante sí un rico escenario, convirtiéndose en espectador del mismo y actuando como puntual analista de los diversos personajes que desfilan por el hogar paterno. Los recuerdos de Mesonero Romanos se retrotraen, pues, a la tertulia paterna y en un contexto cronológico marcado por la revolución de los doceañistas y la Constitución de 1812. Una época que testimonia el dramático divorcio entre una clase media intelectual que ignora a su pueblo y un pueblo poco familiarizado con la ciudadanía que carece del respeto y confianza de su clase intelectual. Bajo el marco de la Constitución de Cádiz, Mesonero refiere las diversas modalidades periodísticas leídas en esta época, su tendencia ideológica, redactores, estilo contenido... Un variopinto periodismo que incluye numerosas formas de presentación y formato: «[...] viose aparecer como llovidos multitud de periódicos, folletos y hojas sueltas, de diversos colores y banderías, desde $E l$ Patriota, que redactaba don José Mor de Fuentes, que era el más simpático a la generalidad, hasta La Pajarera, del festivo escritor don Manuel Casal [...], desde el Redactor General y El Amigo de las Leyes, acérrimos defensores de la banda liberal, hasta la Atalaya de la Mancha, furibundo atleta ultra-realista, en que esgrimía sus armas el padre Castro, monje de San Jerónimo» (1881, I, págs. 111-112). Publicaciones que, en su mayoría, no figuran en las clásicas monografías dedicadas al periodismo ${ }^{4}$. Gómez Imaz (1810) y Antonio Asenjo (1933) dan

No aparece citada en la obra de Eugenio Hartzenbusch (1894). En el Catálogo de las Publicaciones periódicas Madrileñas existentes en la Hemeroteca Municipal de Madrid (1894) tampoco figura La Pajarera, aunque sí, por el contrario, otras publicaciones citadas por Mesonero y que son, igualmente, auténticas curiosidades bibliográficas, como El Patriota, El Redactor General o El Amigo de las Leyes. 
noticia de todo este panorama periodístico aludido por Mesonero. en sus Memorias. En el año 1812 aparecen, según los citados críticos, El Amigo de las Leyes, Anteojos de un Patriota Ciego, El Azote de los Afrancesados, Celoso de la libertad de la Patria, Censor General, El Ciudadano Imparcial, Diario Militar, España Libre, La Faramalla, El Fernandino de Valencia en Madrid, El Filosofo de Antaño en su Gabinete, El Fiscal Patriótico de España. El Imparcial, Mercurio Español, El Observador, El Patriota, La Paxarera, El Publicista Español, Redactor General de España, El Reloxero Universal y El Correo General. En 1813 aparece Atalaya de la Mancha y en 1814 La Abeja Madrileña, continuación de La Abeja Española publicada en Cádiz. También se editan como continuación de los publicados en Cádiz los periódicos El Conciso, El Procurador General de la Nación y del Rey, El Tribunal del Pueblo Español y El Amante de la Libertad Civil. Cierra esta relación los diarios El Universal y El Sol, pertenecientes al año 1814. En enero del citado año, al ser reanudadas en Madrid las sesiones de Cortes de Cádiz, inició también su publicación el Diario de las Cortes, que comenzó a publicarse en el año 1810 en la Real Isla de León. Es evidente, pues, tal como constata Mesonero, la aparición de multitud de periódicos, folletos y hojas. Todo ello gracias a la Ley de Libertad de imprenta que permitió una auténtica eclosión de publicaciones, la mayoría de ellas de periodicidad efímera, en Madrid.

El Trienio Liberal es otro de los periodos comentados con amplitud por Mesonero Romanos. Con razón se refiere a él como una época en la que proliferaban diversas modalidades periodísticas, algunas de difícil ubicación hoy en día. Lo realmente interesante es la disección que Mesonero realiza en torno a las múltiples tendencias del periodismo de esta época constitucional y su opinión sobre la ausencia del político en los medios periodísticos de dicha época. El periodista en el Trienio Liberal no utiliza el periódico para medrar en la política, pues sus miras son otras y los fines están inmersos en los principios constitucionales, en su patriotismo y en la carencia de ambición personal. En este sentido, Mesonero

Material informativo conciso lo ofrece María Cruz Seoane que define la publicación «[...] de gracia ingenu y un tanto chabacana» (1977, pág. 59). Gómez Aparicio (1967, pág. 110) la considera eminentemente satírica y un tanto ingenua.

La Pajarera, generalmente escrito en verso, se hizo célebre por el título de los sucesivos números que se iban publicando, pues llevaban el nombre de un pájaro. El nombre correspondiente a dicho pájaro -Cernícalo, Mirlo, Urraca, Cuco, Cuervo, etc.- arremetía sus picotazos contra la sociedad. Su director fue Manuel Casal, más conocido con el seudónimo Don Lucas Alemán, poeta, médico y colaborador en diversos periódicos madrileños de índole satírica (Gil Novales, 1991, págs. 132-133). 
indica que todavía «no se había dado el caso de pasar desde la redacción de un periódico a un sillón ministerial, a un consejo o a una embajada» (I, pág. 246) ${ }^{\text {s. }}$.

Las primeras publicaciones periódicas que aprovecharon la libertad de prensa en el Trienio Liberal y «formaron iglesia o reunieron clientela», en el decir de Mesonero, fueron de tendencia afrancesada-liberal. Grupo compuesto, generalmente, «[...] de hombres de orden y de doctrina, aunque visiblemente desafectos a la Constitución vigente, y por ende mal vistos entre la mayoría del público, que por entonces se declaraba radicalmente afecto a la revolución y sus consecuencias» (I, pág. 242). En este primer grupo Mesonero destaca la publicación de El Universal, periódico magro redactado por Manuel Narganes, José María Galdeano, José Rodríguez y Juan Caborreluz, entre otros. El Universal, que se publicó desde el 12 de mayo de 1820 hasta el 23 de abril de 1823, era conocido con el sobrenombre de Sabanón debido a su gran tamaño ( $382 \times 227 \mathrm{~mm}$.). En el sentir de Mesonero sus redactores defendieron con decoro sus opiniones y doctrinas, aunque su enfoque y análisis sobre la Constitución eran un tanto confusos, pues explicaron a su modo los decretos llevados a cabo por las Cortes.

En esta línea de periódicos afrancesados surge una publicación, El Imparcial, que es juzgada por Mesonero como más refractaria que El Universal a las doctrinas constitucionales. Publicación que inició su andadura el 10 de septiembre de 1821 y debió cesar hacia el mes de junio, tal como indican Hartzenbusch (1894), Gil Novales (1975) y Gómez Aparicio (1967)6. El Imparcial fue uno de los periódicos más representativos e importantes de la contrarevolución, dirigido por Javier de Burgos, escritor que sufrió las censuras del periodismo burlón y exaltado. Cierra esta trilogía ofrecida por Mesonero $E l$

${ }^{5}$ La única excepción la constituye el general San Miguel, aunque no por su condición de periodista sino por su intervención militar en el levantamiento de la isla de León. Por otro lado, insiste Mesonero, «los ministros, diputados y hombres importantes de aquella época, y que casi todos procedían de la anterior, de Cádiz, ni Arguielles, ni Martínez de la Rosa, ni Calatrava, ni Toreno, ni Canga, ni Feliu, ni Moscoso, etc. fueron periodistas jamás» (I, pảg. 246).

"Hartzenbusch indica textualmente lo siguiente: «La colección que he visto alcanza hasta el núm. CCXVI, correspondiente al 30 de junio de 1822, cuyo número, si no es el último, se me figura que pocos más saldrían después» (1894, pág. 32). Por su parte Gil Novales emite en torno a la fecha de 30 de junio de 1822 una interrogante (1975, II, pág. 1021). Gómez Aparicio hace coincidir su cese el 7 de julio de 1822 con la ola de represalias que los exaltados protagonizaron a raíz de la intentona absolutista en la noche del 7 de julio de 1822. El Censor también sufriría las consecuencias de esta situación de irritabilidad por la que atravesaba España, cesando su publicación el 13 de julio del mismo año mediante el siguiente comunicado: «Aviso a los suscriptores.- Los redactores de El Censor, considerando que en tiempos de agitaciones políticas, y cuando están exasperados los ánimos, la censura ofende e irrita, pero no corrige, han acordado terminar su obra con el presente número», El Censor. Periódico político y Literario, Madrid, Imprenta de El Censor, 7 de julio de 1822, pág. 1. 
Censor, definida concisamente y con precisión en sus Memorias, pues percibe claramente la dualidad de su contenido: el político y el literario. Desde la óptica política El Censor se muestra desde un primer momento como uno de los principales órganos de la contrarevolución, redactado por los ilustres afrancesados Lista, Miñano, Hermosilla y Reinoso (Le Gentil, 1909, pág. 10, pássim. $)^{7}$. En lo concerniente a la parte literaria, el nombre de El Censor figura en un lugar privilegiado, pues sus reseñas críticas y literarias fueron consideradas siempre con palabras elogiosas, especialmente, por los defensores del neoclasicismo. Publicación que no podía pasar por alto el propio Mesonero Romanos, pues en ella figura el germen de un costumbrismo que alcanzaría su máxima difusión en la década posterior. Cabe recordar a tal respecto a Sebastián Miñano, autor de las célebres, certeras y mordaces cartas políticas tituladas Lamentos políticos de un Pobrecito Holgazán que estaba acostumbrado a vivir a costa ajena.

Frente a esta trinidad periodística ofrecida por el propio Mesonero en sus Memorias surge una multitud de «periódicos diarios, terciarios, semanales, quincenales y sin periodo fijo, bajo los nombres más halagüeños, tales como $\mathrm{La}$ Aurora, La Ley, El Constitucional, La Libertad, El Sol, El Correo Liberal, El Independiente, El Conservador, El Patriota Español, El Eco de Padilla, etc. que aparecían y desaparecían alternativamente, o se refundían unos en otros, despedazándose mutuamente con la mayor cordialidad y formando un tutti infernal, que dio origen a la discreta y agudísima sátira que les prodigaba a manos llenas el folleto intercandente titulado La Periodicomanía, que redactaba el abogado D. Francisco Camborda» (I, págs. 243-244). Razón tiene Mesonero Romanos al afirmar que La Periodicomanía ${ }^{8}$ surge en un momento asaz candente y complicado,

Los artículos referidos a la política fueron redactados mayoritariamente por Hermosilla. Publicación definida por la crítica con el calificativo de excelente y con toda suerte de elogios, como en el caso de María Cruz Seoane: «La energía y serenidad con que estos hombres [Lista y Hermosilla] defendieron su difícil postura, equidistante del absolutismo y del constitucionalismo extremado, se simpatice o no con ella, merece respeto y aprecio. La conducta posterior de Hermosilla y Miñano, sin embargo, se lo resta. Cuando se lee la Histoire de la Revolution que publicó Miñano en 1824 y se comparan las ideas expuestas con las del Pobrecito Holgazán, la diferencia sólo puede explicarse por un espíritu de vil adulación al deseado -tirano- seducido nuevamente tirano Fernando, o de odio y mezquino afán de revancha contra los liberales, que ni siquiera el duro trato que éstos le habían dispensando a él y a su amigos puede disculpar. En cuanto a Lista, figura por muchos motivos venerable, singularmente como pedagogo, no lo es por cierto por su conducta política. Ya había dado muestras de inconsecuencia pasando de patriota a afrancesado durante la Guerra de la Independencia. Después del Trienio Liberal pasó a sustentar doctrinas más retrógradas que las manifestadas en $E l$ Censor en la oficiosa Gaceta de Bayona, para a partir de 1833 convertirse en defensor de todos los gobiernos de distintos matices que se sucedieron» (1977, pág. 133)

${ }^{8}$ La Periodicomanía (1820-1821) aparece sin fecha ni periodo fijo. Cada número suelto costaba trece cuartos y tenía airededor de veinticuatro páginas. Las medidas del mismo son Om, 
pues las publicaciones periódicas hacen gala de una mordacidad poco común. Bajo este marco constitucional surge La Periodicomanía en el año 1820 con un claro propósito: analizar todas las publicaciones de la época, su duración, ideología, formato y disposición. La sátira aludida por Mesonero Romanos, canalizada a través de La Periodicomanía, se materializa, especialmente, en los conocidos epitafios que publicaba en sus números. El fallecimiento de los periódicos protagonizaba el epitafio o epitafios que figuran en las páginas de La Periodicomanía .

Conjunto periodístico que el propio Mesonero resume, define y clasifica con precisión, pues establece dos marcos referenciales. Por un lado, publicaciones abanderadas por el partido exaltado, en contraposición el moderado, que representaba El Universal; por otro, periódicos cuya denominación sería la de ultraliberales -El Tribuno, El Eco de Padilla, El Conservador (por antífrasis)-. En este último grupo de periódicos colaboraban los más fanáticos representantes del bando comunero. En el sentir de Mesonero, todo este conjunto de periódicos marcó las directrices de un copioso número de folletos, papeles o periódicos en general cuyo fin primordial era la sátira mordaz y agresiva contra los representantes del poder religioso o civil. El Compadre del Holgazán, La Cotorrita, El Cajón de Sastre, Las Semblanzas de los Diputados, El Zurriago, La Tercerola constituyen la principal semblanza de un periodismo incisivo y burlón. Mesonero

$118 \times 0 \mathrm{~m}, 0$ "66. Se publicaron cuarenta y tres números. En el núm. 1 de La Periodicomanía se alude al precio de la publicación: «Cada cual soltará sus trece cuartitos, según tarifa, porque así se han empezado a vender otros cuadernos, y es justo seguir la loable; y porque este periódico es una propiedad nuestra, y cada uno vende como le acomoda, y porque si no vendiere (lo que Dios no permita), nos quedaríamos gastados, aburridos, y sin oficio» [1 (1823), págs. 6-7]. Cfr. Rubio Cremades (1984 y 1985).

'La burla o sátira no sólo se percibe en dichos epitafios, sino también en los momentos que la publicación está viva y no fenecida. Por ejemplo en una de las secciones creadas en La Periodicomanía -"Hospital general de incurables"-, se emiten juicios o diagnósticos sobre las enfermedades de los periódicos y las causas de dichas enfermedades, así como los remedios para su curación:

El Universal. Padece extenuación, flojedad en el sistema nervioso, inapetencias, sudores fríos. Método curativo. Tónicos: tintura de quina, baños termales, ejercicios a caballo. das saladas.

El Espectador. Hemoptisis. Leche de burra, caldos ligeros, ácido nítrico y abstinencia de vian-

La Miscelánea. Flatos histéricos. Jarabe de adormideras blancas y de corteza de cidra, agua de canela, paseo, bailes y diversiones

El Eco de Padilla. Vértigos. Purgas, sangrías y sanguijuelas, lavativas emolientes, agua nitrada y ejercicio moderado.

Diario Viejo de Madrid. Consunción, insomnios, vómitos, diarrea. Sueros, sustancia de pan, y paños de agras, y triaca al vientre.

El Censor. Calenturas intermitentes. Emético, quina y aguas de naranja, entre caldo y caldo. 
Romanos da cuenta de un profundo conocimiento de la prensa del Trienio Liberal, pues percibe los rasgos esenciales de las publicaciones citadas. Su tendencia ideológica, colaboradores, historial de sus fundadores, etc. constituyen los principales soportes que sobre el periodismo figuran en sus Memorias. Es, por ejemplo, su concisa y precisa información ofrecida sobre el periódico El Zurriago y La Tercerola, su hermano, que alcanzaron «la funesta gloria de desmoralizar políticamente al pueblo y hacer descarriar la revolución hasta lanzarla al abismo»"10.

La segunda época de las Memorias de un setentón se inicia con el estudio de las costumbres de la sociedad madrileña. Material noticioso que remite al lector a la juventud literaria de los años que precedieron al Trienio Constitucional. La restauración absolutista, la abolición de la Ley Sálica por Fernando VII, la Regencia de María Cristina y el Estatuto Real de Martínez de la Rosa constituyen los hitos más relevantes en los que enmarca la información relativa al periodismo. Proceso histórico en el que no está ausente la referencia al periodismo, a su especial incidencia en la sociedad española. De todo este mosaico de opiniones vertidas por Mesonero en la segunda parte de sus Memorias destaca el párrafo que tiene como objetivo esencial el análisis del «monstruo de cien lenguas apellidado la prensa periódica, que no hay suceso que no registre en todos sus detalles, hecho que no comente, reputación que no eleve, analice o destruya, ya con el escalpelo de la crítica severa, ya con el cascabel de la sátira, con más primor y talento que el que pudiera prestarle mi vetusto y descolorido pincel» (II, pág. 175).

El panorama periodístico ofrecido en esta ocasión atañe a la década transcurrida entre 1833 y 1843 . Es evidente que la férrea censura ejercida por Fernando VII impidió la publicación de periódicos y revistas en general. Tan sólo algunas publicaciones adictas al absolutismo fernandino o de contenido comercial y mercantil tuvieron la fortuna de editarse en la década comprendida entre el final del periodo constitucional (1823) y la muerte de Fernando VII (1833). El Realista, El Restaurador, Diario Literario-Mercantil, Correo Literario y

${ }^{10}$ De horrible papel lo califica Mesonero, escrito en prosa y verso no exento de cierto gracejo, aunque por extremo desaliñado y procaz. Publicación debida a Luis Mejías y Benigno Morales. Mesonero Romanos lo cita en varias ocasiones y en función de los apodos que dicha publicación daba a determinados hombres de Estado. Martínez de la Rosa era conocido con el sobrenombre de Rosita la Pastelera. El jefe político San Martín fue «bautizado» con el nombre de Tin-Tin y el capitán general Morillo con el apodo Trabuco. Mesonero también recoge el sobrenombre que El Zurriago daba a los ministros, denominándolos pasteleros, camarilleros y anilleros. Toda una nomenclatura que sería inventada por El Zurriago y que caló profundamente tanto en los medios políticos como sociales en general (Gil Novales, 1975; Zavala, 1967). 
Mercantil, Semanario de Agricultura y Artes... no son sino elocuentes ejemplos de la escasez de publicaciones periódicas, de ahí que Mesonero silenciara su

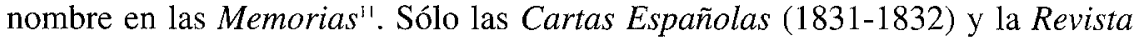
Española (1832-1836) se libran de esta lógica poda y figuran en un lugar señero, analizadas y citadas en más de una ocasión.

Al igual que en anteriores ocasiones, Mesonero realiza una clasificación de la prensa desde el punto de vista ideológico. De esta forma aúna periodistas y periódicos en compartimentos de ideología afín. Gracias a este material reunido tenemos noticia de la prensa moderada (El Correo Nacional, La España, El Corresponsal, El Heraldo) y de sus colaboradores (Ríos Rosas, Donoso Cortés, Villalta, González Bravo, Sartorius...). En segundo lugar aparece la prensa progresista, abanderada por El Eco del Comercio, que tuvo pronto fieles imitadores, como El Clamor Público, fundado y dirigido por Fernando Corradi, El Castellano, dirigido por Aniceto de Álvaro y redactado por Díez Canseco y Llorente Flórez. Por último en «el sentido más o menos retrógrado», según palabras del propio Mesonero, aparece la prensa absolutista, encabezada por $L a$ Esperanza y custodiada por otras de idéntico credo, como El Católico y El Pensamiento de la Nación, este último redactado por Jaime Balmes. El juicio de Mesonero respecto a este periodismo retrógrado tiene sus matizaciones, al menos en lo que respecta a la publicación El Pensamiento de la Nación. En primer lugar porque su fundación no fue una idea nacida del propio Balmes, sino de un grupo de políticos tradicionalistas conscientes del cambio que se operaba en la sociedad española en estos tiempos, $y$, en segundo lugar, el loable, aunque discutido intento de canalizar la reconciliación española mediante el matrimonio de Isabel II con el primogénito de don Carlos. Estas son las coordenadas más interesantes que aglutina El Pensamiento de la Nación. Por el contrario, el resto de las otras publicaciones que figuran en este sector retrógrado, como La Esperanza, sí hacen gala del más férreo credo carlista.

Como es habitual en Mesonero Romanos, la prensa satírica encuentra siempre un lugar privilegiado en las correspondientes disecciones que de la prensa periódica lleva a cabo. Corriente periodística encabezada por contertulios y amigos del propio Mesonero, como los célebres escritores Larra, Segovia, Pelegrín,

"En el capítulo II, Ojeada a la época Calomardina, Mesonero Romanos refiere con no poco dolor el estado cático por el que atraviesa España, atenazada por el absolutismo más obscurantista. Mesonero refiere parte de esta desolación referida a la libertad de prensa en las líneas que a continuación ofrecemos: «Cerraron las Universidades, prohibiéndose rigurosamente la entrada de los diarios extranjeros, y cesó, en fin, la publicación de todo lo que pudiese oler a ilustración y patriotismo» (II, pág. 48) 
Bretón, Villergas... Publicaciones como El Guirigay, El Huracán, El Mundo, La Posdata y Fray Gerundio, entre otras, son probada muestra de una prensa mordaz y agresiva. Tal vez falta en este panorama periodístico realizado por Mesonero los nombres de otras no menos incisivas y humorísticas publicaciones, como $\mathrm{El}$ Jorobado, El Mata-Moscas, Fray Junípero, La Risa, La Tarántula... Aun así, las publicaciones citadas por Mesonero son harto representativas, especialmente la titulada Fray Gerundio ${ }^{12}$.

Las publicaciones de claro matiz literario ocupan un lugar privilegiado en las Memorias de un setentón, especialmente Cartas Españolas, Revista Española y el Semanario Pintoresco Español. La primera de ellas la analiza desde múltiples ópticas. En unas ocasiones relacionando sus opiniones con la controvertida actitud de su fundador, Carnerero; en otras con el proyecto de su obra costumbrista y en interrelación con la obra de escritores adscritos a dicho género. Respecto a Revista Española cabe señalar, una vez más, la pertinaz insistencia en analizar la figura de Carnerero ${ }^{13}$ desde óptica negativa. Aun así, las alusiones más interesantes corresponden a las relaciones literarias y amistosas entre el propio Mesonero y Larra, pues desvelan aspectos harto significativos que no sólo atañen a la peculiar forma de sus artículos de costumbres, sino también al carácter y personalidad de Fígaro. Respecto a las páginas dedicadas a la fundación del Semanario Pintoresco Español nada nuevo aportan al conocimiento de su fundación. Se trata en realidad de un extracto de lo publicado en el primer número del Semanario. Frente a la extensa explicación sobre las circunstancias que motivaron su fundación en dicha publicación ilustrada, lo reunido en sus Memorias es una simple visión que incide en los mismos planteamientos: difusión de un perio-

12 Fundada y redactada por el conocido escritor costumbrista Modesto Lafuente, Fray Gerundio, de honda formación humanística, teológica y filosófica. Irónico, chocarrero, sarcástico y, en ocasiones, amargo, reencarnó en el sentenciador Fray Gerundio a don Quijote, y en el ladino Tirabeque al buen Sancho. Los diálogos entre el fraile y el lego son aleccionadores, pues mientras Tirabeque habla de la España plagada de defectos, Fray Gerundio se refiere a la España virtuosa, intachable que quisiera conocer. Desde esa perspectiva nace lo mejor de su sátira y lo más cruel de sus ironías, pues se pone en ridículo la venalidad de los políticos que mantienen a España en el marasmo.

${ }^{13}$ Sirva como botón de muestra el párrafo que a continuación extractamos del capítulo Episodios literarios. El teatro y los poetas: «[Carnerero] pudo obtener de Fernando VII el privilegio exclusivo de publicar un periódico o revista literaria, que tituló Cartas Españolas, y que, como buen cortesano, pero bajo el amparo y protección de la Reina María Cristina; y cuando esta augusta señora se encargó de la gobernación del reino, a continuación de la muerte de Fernando VII, Carnerero, obediente como un girasol, fundó la Revista Española, hallando en ella el medio de prodigar el humo de su incienso a los diversos matices políticos que se sucedieron, hasta que en 1838, falto de fuerzas físicas y sobrado de achaques adquiridos en su vida accidentada, arrojó su incensario a las plantas (que no a las raíces) del altísimo Mendizábal» (II, págs. 67-68). 
dismo literario, popular y pintoresco en donde no ha lugar la crónica ni el debate. político.

Las Memorias de un setentón son, pues, un material noticioso de no poca relevancia para el conocimiento de la prensa periódica española. El cambio generacional, los sucesivos episodios históricos que se van desgranando a lo largo de estas memorias, posibilitan un mayor entendimiento y comprensión sobre la figura del periodista. La valoración que del mismo lleva a cabo desde una perspectiva diacrónica es harto orientativa, pues el lector tiene la sensación de asistir al nacimiento de una profesión, la del periodista, que se irá consolidando en el último tercio del siglo XIX.

\section{BIBLIOGRAFÍA}

ASENJO, Antonio. 1933. La prensa madrileña a través de los siglos (Apuntes para su historia desde el año 1661 al de 1925), Madrid, Artes Gráficas Municipales.

CABALLÉ, Anna. 1995. Narcisos de tinta. Ensayo sobre la literatura autobiográfica en lengua castellana (Siglo XIX y XX), Málaga, Megazul.

1933. Catálogo de las Publicaciones periódicas madrileñas existentes en la Hemeroteca Municipal de Madrid, Madrid, Artes Gráficas Municipales.

DURÁN LÓPEZ, Fernando. 1997. Catálogo comentado de la autobiografía española (Siglos XVIII y XIX), Madrid, Ollero \& Ramos, Editores.

ESCOBAR, José. 1993. «Memorias de un setentón en la literatura de su tiempo», en De místicos y mágicos, clásicos y románticos. Homenaje a Ermanno Caldera, Messina, Armando Siciliano Editore, págs. 269-287.

GIL NOVALES, Alberto. 1975. Las sociedades patrióticas (1820-1823), Madrid. Tecnos [Apéndice VI, «Los colaboradores de El Zurriago y de La Tercerola», II, págs. 1048-1061].

- 1991. Diccionario Biográfico del Trienio Liberal, Madrid, Ediciones El Museo Universal.

GÓMEZ APARICIO, Pedro. 1967. Historia del periodismo español. Madrid, Editora Nacional, 3 vols. 
GÓMEZ IMAZ, Manuel. 1810. Los periódicos durante la Guerra de la Independencia (1808-1814), Madrid, Revista de Archivos, Bibliotecas y Museos.

HARTZENBUSCH, Eugenio. 1894. Apuntes para un catálogo de periódicos madrileños desde el año 1661 al 1870, Madrid, Establecimiento Tipográfico «Sucesores de Rivadeneyra».

LE GENTIL, George. 1909. Les Revues litteraires de l'Espagne pendant la première motié du XIX siècle. Apperçu bibliographique, Paris, Hachette.

MESONERO ROMANOS, Ramón de. 1881. Memorias de un setentón, natural y vecino de Madrid, Madrid, Oficina de la Ilustración Española y Americana.

- 1994. Memorias de un setentón, ed. J. Escobar y J. Álvarez Barrientos, Madrid, Castalia-Comunidad de Madrid, [Clásicos Madrileños].

ROMERA CASTILLO, José. 1999. «Escritura autobiográfica», Signa, 8, págs. 168-170.

RUBIO CREMADES, Enrique. 1984 y 1985. «La Periodicomanía en el Trienio Liberal», Anales de Literatura Española, 3, págs. 429-446; 4, págs. 383-414.

- 2000. Periodismo y Literatura: Mesonero Romanos y el Semanario Pintoresco Español, Alicante, Publicaciones de la Universidad de Alicante.

SEOANE, María Cruz, 1977. Oratoria y periodismo en la España del siglo XIX, Madrid, Fundación Juan March-Editorial Castalia.

ZAVALA, Iris M. 1967. «La prensa exaltada en el Trienio Constitucional», Bulletin Hispanique, LXIX, 3-4, págs. 365-388. 